\title{
Persistência da fitomassa de Urochloa brizantha em cobertura em função da aplicação de serpentinito
}

Persistence of Urochloa brizantha phytomass in top dressing as a function of serpentinine application

Persistencia de la fitomasa de Urochloa brizantha en el aderezo en función de la aplicación de serpentina

Alves Alexandre Alovisi

ORCID: https://orcid.org/0000-0002-5401-717X

Universidade Federal da Grande Dourados, Brasil

E-mail: alves.snpconsultoria@gmail.com

Alessandra Mayumi Tokura Alovisi

ORCID: https://orcid.org/0000-0003-4236-4446

Universidade Federal da Grande Dourados, Brasil E-mail: alessandraalovisi@ufgd.edu.br

Luiz Carlos Ferreira de Souza

ORCID: https://orcid.org/0000-0002-9216-5077

Universidade Federal da Grande Dourados, Brasil E-mail: luizsouza@ufgd.edu.br

Luana Gonçalves Perondi

ORCID: https://orcid.org/0000-0003-1321-9012

Universidade Federal da Grande Dourados, Brasil

E-mail: luanaperondy@gmail.com

Luciene Kazue Tokura

ORCID: https://orcid.org/0000-0001-9758-0141

Universidade Estadual do Oeste do Paraná, Brasil

E-mail: lucienetokura@gmail.com

Giuliano Reis Pereira Muglia

ORCID: https://orcid.org/0000-0002-9590-4226

Universidade Federal da Grande Dourados, Brasil

E-mail: giulianormp2@hotmail.com

Robervaldo Soares da Silva

ORCID: https://orcid.org/0000-0002-0214-4820

Universidade Federal da Grande Dourados, Brasil

E-mail: robervaldo.soares@yahoo.com.br

Willian Isao Tokura

ORCID: https://orcid.org/0000-0001-9363-793X

Universidade Federal de Goiás, Brasil

E-mail: willianisaotokura@hotmail.com

Cleidimar João Cassol

ORCID: https://orcid.org/0000-0002-2433-7084

Universidade Federal da Grande Dourados, Brasil

E-mail: cleidimar_cassol@hotmail.com

Priscila Marques Kai

ORCID: https://orcid.org/0000-0002-4767-3718

Universidade Federal da Grande Dourados, Brasil

E-mail: priscila.kai@hotmail.com

Meriane Melissa Taques

ORCID: https://orcid.org/0000-0003-2578-5812

Universidade Federal da Grande Dourados, Brasil

E-mail: meriane.taques@gmail.com 


\begin{abstract}
Resumo
A aplicação de serpentinito pode diminuir a acidez do solo aumentando a disponibilidade de $\mathrm{Ca}, \mathrm{Mg}, \mathrm{Pe} \mathrm{Si} \mathrm{às} \mathrm{plantas.}$ O Objetivo deste trabalho foi avaliar a influência do serpentinito na produção de matéria seca da parte aérea da forrageira Urochloa brizantha cv. Piatã e decomposição da fitomassa da forrageira. O delineamento experimental empregado foi blocos casualizados em parcelas sub-subdivididas no tempo, sendo as doses de serpentinito nas parcelas $\left(0,2,4,8\right.$ e $\left.16 \mathrm{mg} \mathrm{ha}^{-1}\right)$, o uso de bioativo nas subparcelas (com e sem o uso de bioativo) e as épocas de avaliação nas subsubparcelas $(0,30,60,90,120$ e 150 dias após o manejo). As variáveis analisadas foram: taxa de cobertura da fitomassa sobre o solo, massa remanescente, tempo de meia vida e constante de decomposição da fitomassa da forrageira. A aplicação do serpentinito proporcionou maior produtividade de matéria, aumentou a taxa de cobertura e massa remanescente da fitomassa da Urochloa brizantha sobre o solo. O uso do bioativo proporcionou maior produção de matéria seca da forrageira com menores doses de serpentinito.
\end{abstract}

Palavras-chave: Silicato de magnésio; Cobertura do solo; Decomposição palhada; Correção do solo; Forrageira.

\begin{abstract}
Serpentinite application can reduce soil acidity by increasing $\mathrm{Ca}, \mathrm{Mg}, \mathrm{P}$, and $\mathrm{Si}$ to plants. The objective of this work was to evaluate the influence of serpentinite on the production of shoot dry matter of the forage Urochloa brizantha cv. Piatã and forage phytomass decomposition. The experimental design used was randomized blocks in sub-divided plots in time, with the doses of serpentinite in the plots $\left(0,2,4,8\right.$, and $\left.16 \mathrm{mg} \mathrm{ha}^{-1}\right)$, the use of bioactive in the subplots (with and without the use of bioactive) and the evaluation times in the sub-sub plots $(0,30,60,90,120$ and 150 days after management). The variables analyzed were: phytomass coverage rate on the ground, remaining mass, half-life, and constant forage phytomass decomposition. The application of serpentinite provided higher matter productivity, increased the coverage rate and the remaining mass of Urochloa brizantha phytomass on the soil. The use of the bioactive provided more excellent forage dry matter production with lower doses of serpentinite.
\end{abstract}

Keywords: Magnesium silicate; Ground cover; Straw decomposition; Soil correction; Forage.

\title{
Resumen
}

La aplicación de serpentinita puede reducir la acidez del suelo al aumentar la disponibilidad de Ca, Mg, P y Si para las plantas. El objetivo de este trabajo fue evaluar la influencia de la serpentinita en la producción de materia seca de brotes del forraje Urochloa brizantha cv. Descomposición de piatã y fitomasa forrajera. El diseño experimental utilizado fue bloques al azar en parcelas subdivididas en el tiempo, con las dosis de serpentinita en las parcelas $(0,2$, 4,8 y $16 \mathrm{mg} \mathrm{ha}^{-1}$ ), el uso de bioactivo en las subparcelas (con y sin uso de bioactivo) y los tiempos de evaluación en las sub-subparcelas $(0,30,60,90,120$ y 150 días después del manejo). Las variables analizadas fueron: tasa de cobertura de fitomasa en el suelo, masa remanente, vida media y constante de descomposición de fitomasa del forraje. La aplicación de serpentinita proporcionó una mayor productividad de la materia, aumentó la tasa de cobertura y la masa restante de fitomasa de Urochloa brizantha en el suelo. El uso del bioactivo proporcionó una mayor producción de materia seca forrajera con menores dosis de serpentinita.

Palabras clave: Silicato de magnesio; Cobertura del suelo; Descomposición de la paja; Corrección de suelos; Forraje.

\section{Introdução}

Os solos de Cerrado, em sua maioria, apresentam avançado intemperismo, elevada acidez, baixa disponibilidade de nutrientes e silício ( $\mathrm{Si}$ ) para as plantas, por isso, é necessário realizar constantes correções e adubações para que se elevem os potenciais produtivos. O serpentinito é uma rocha de origem metamórfica, ultrabásica formada principalmente por dolomita, calcita e sílica, portanto, uma fonte rica em magnésio e cálcio com teores de até $42 \%$ de $\mathrm{MgO}$, podendo contribuir no balanceamento da relação $\mathrm{Ca} / \mathrm{Mg}$ do solo, além de apresentar elevadas quantidades de silício (até $45 \%$ de $\mathrm{SiO}_{2}$ ) entre outros minerais, contribuindo para a reposição desses minerais no solo (Friedman, 2013).

As características do serpentinito, quando avaliadas como corretivos de acidez, atendem os limites especificados pela Instrução normativa vigente do Ministério da Agricultura, Pecuária e Abastecimento. A influência do serpentinito na correção da acidez do solo é verificada pelo aumento do $\mathrm{pH}$ na solução do solo, e consequente redução do teor de $\mathrm{Al}^{3+}$ trocável e o aumento dos teores de $\mathrm{Ca}^{2+}$ e $\mathrm{Mg}^{2+}$ trocáveis. A existência de dolomita na composição da rocha sugere que a mesma seja considerada um insumo agrícola de ação lenta. Assim, o serpentinito possui potencial para aplicação na agricultura como corretivo de solos, fornecedor de nutrientes e silício o que torna o seu estudo uma contribuição para o crescimento da agricultura sustentável no país. 
Segundo Tavares et al. (2010) o serpentinito pode ser definido com um silicato de cálcio e magnésio com teores médios de $\mathrm{SiO}_{2}$ e $\mathrm{MgO}$ de 40,56 e 45,70\%, respectivamente. Teixeira et al. (2010) consideram o serpentinito com um pó de rocha silicatada com características químicas necessárias para ser considerado um corretivo de solo.

A utilização de rochas portadoras de nutrientes representa, atualmente, uma prática alternativa para complementação ou substituição parcial das adubações convencionais na agricultura. Contudo, pó de rochas geralmente apresentam baixa solubilidade (Alovisi et al., 2021). Assim sendo, tem-se buscado processos de tratamento que venham a incrementar a solubilização e agregar valor aos produtos derivados de rochas. Visando essa problemática, a agricultura moderna tem investido em tecnologias como a utilização de produtos bioativadores da microbiota do solo e atividade fotossintética vegetal promovendo a redução dos custos de produção, menor degradação ambiental, aumento da qualidade do solo e mantendo ou aumentando a produtividade das culturas (Trentin et al. 2014).

O bioativo tem a tecnologia penergetic que se baseia no processo de energização, ou seja, ondas eletromagnéticas em espectro reduzido, inofensiva a qualquer organismo vivo, que atua na indução da atividade biológica observada naturalmente nos sistemas solo-micro-organismos (Penergetic, 2021). Segundo Ceribolla (2015) o penergetic ao ser aplicado sobre o solo, induz a atividade microbiana, resultando em uma maior atração de microrganismos e por consequência acelera a mineralização , em especial, os nutrientes fósforo e potássio.

A produção e a manutenção de palhada sobre a superfície do solo são as principais premissas para o sucesso do sistema plantio direto (SPD), principalmente em regiões tropicais onde as elevadas temperaturas e umidade aceleram a decomposição dos resíduos. Desse modo, o estabelecimento de cobertura do solo com plantas semeadas para essa finalidade, além de rotações de cultura, constitui um desafio para o SPD na região. Soma-se a isto ao fato de que as condições climáticas da primavera-verão condicionam alta taxa de decomposição desse material, de tal forma que a cobertura do solo é reduzida rapidamente, devendo haver aporte constante desse material ao solo.

Portanto, para que as plantas de cobertura possam contribuir, de maneira mais eficiente possível, no sistema plantio direto, tanto no aspecto físico como no químico, é necessário que se tenha maior conhecimento sobre o processo de decomposição de sua fitomassa, pois a ciclagem de nutrientes via plantas de cobertura de solo desempenha um papel importante em sistemas agrícolas e o conhecimento da dinâmica de decomposição dos resíduos culturais é fundamental para maximizar o aproveitamento dos nutrientes pela cultura em sucessão. Neste sentido, é importante selecionar plantas de cobertura que apresentem elevada capacidade de produção de massa seca, ciclagem de nutrientes e impacto nos atributos químicos do solo e na resposta das culturas subsequentes. Segundo Dantas et al. (2016) a Urochloa brizantha é uma forrageira considerada adaptada para as épocas de menor disponibilidade hídrica como a safrinha, por apresentar boa produtividade de forragem nessas condições.

O estudo com plantas de cobertura em interação com a neutralização da acidez do solo pelo serpentinito torna-se oportuno para o conhecimento da real contribuição da persistência dos resíduos culturais na superfície do solo. Diante do exposto, o objetivo foi avaliar a ação do serpentinito e bioativo na produção de matéria seca da parte aérea da forrageira Urochloa brizantha cv. Piatã e decomposição da fitomassa da forrageira.

\section{Metodologia}

\subsection{Localização e caracterização da área experimental}

O experimento foi realizado na Fazenda Experimental de Ciências Agrárias da Universidade Federal da Grande

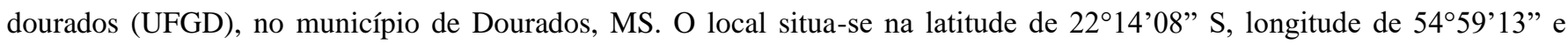
altitude de $434 \mathrm{~m}$. O solo foi caracterizado como Latossolo Vermelho Distroférrico (Santos et al., 2018). A área onde o experimento foi conduzido já era cultivado com culturas anuais (principalmente soja, milho e trigo) há mais de 20 anos. 
Conforme a classificação de Köppen o clima é do tipo Am (Alvares et al., 2013), com precipitação média anual de 1.400 mm, e as temperaturas médias variam de $18^{\circ} \mathrm{C}$ a $25^{\circ} \mathrm{C}$ nos meses mais frio e mais quente, respectivamente. As condições climáticas no decorrer do experimento estão ilustradas na Figura 1.

Figura 1 - Precipitação pluviométrica e temperaturas máxima e mínima registradas durante o experimento, no período de janeiro de 2015 a agosto de 2016 em Dourados- MS.

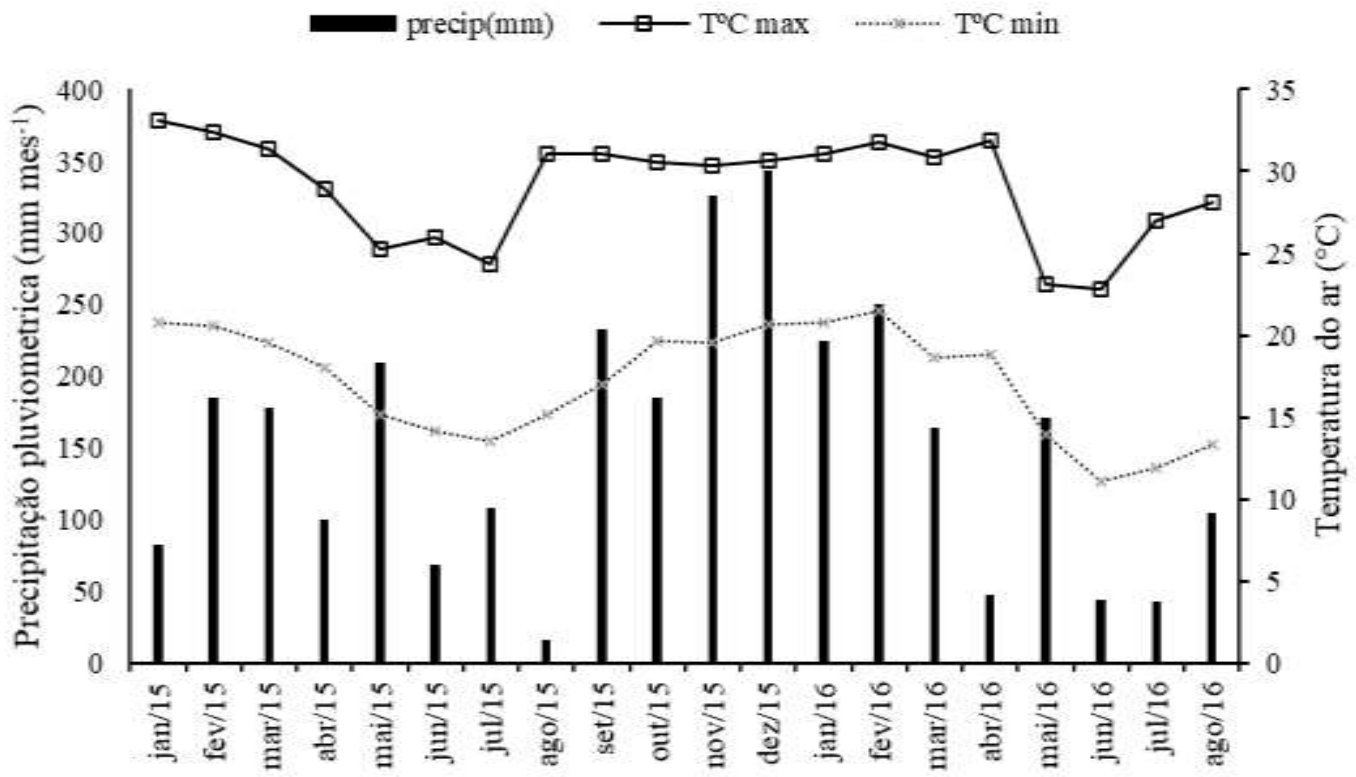

Fonte: Autores.

\subsection{Delineamento experimental e tratamentos}

O delineamento utilizado foi em blocos casualizados, com quatro repetições. Para as avaliações da palhada da Urochloa, os tratamentos foram casualizados no esquema de parcelas sub-subdivididas, sendo que nas parcelas utilizou-se cinco doses de serpentinito $\left(0,2,4,8\right.$ e $\left.16 \mathrm{Mg} \mathrm{ha}^{-1}\right)$, nas sub-parcelas o uso de bioativo (com e sem) e nas sub-subparcelas foram alocadas as épocas de avaliação (0, 30, 60, 90, 120 e 150 dias) após o manejo (corte) da Urochloa.

\subsection{Condução do experimento}

A caracterização dos atributos químicos do solo, antes da aplicação do serpentinito foi efetuado nas profundidades de 0,0-0,10 e 0,10-0,20 m. As determinações químicas do solo seguiram a metodologia descrita por Silva (2009), com os seguintes resultados: $\mathrm{pH}$ em água: 5,7 e 5,4; $\mathrm{pH} \mathrm{CaCl} 2: 5,0$ e 4,6; $\mathrm{Ca}\left(\mathrm{cmol}_{\mathrm{c}} \mathrm{dm}^{-3}\right): 3,6$ e 1,5; $\mathrm{Mg}\left(\mathrm{cmol}_{\mathrm{c}} \mathrm{dm}^{-3}\right): 1,9$ e 0,9; K $\left(\mathrm{cmol}_{\mathrm{c}} \mathrm{dm}^{-3}\right): 0,27$ e 0,$11 ; \mathrm{Al}\left(\mathrm{cmol}_{\mathrm{c}} \mathrm{dm}^{-3}\right): 0$ e 0,$6 ; \mathrm{H}+\mathrm{Al}\left(\mathrm{cmol}_{\mathrm{c}} \mathrm{dm}^{-3}\right): 6,1$ e 5,7; $\mathrm{SB}\left(\mathrm{cmol}_{\mathrm{c}} \mathrm{dm}^{-3}\right): 119$ e 82; P Mehlich-1 (mg $\left.\mathrm{dm}^{-3}\right): 16,4$ e 4; $\mathrm{MO}\left(\mathrm{g} \mathrm{dm}^{-3}\right): 27$ e 17 e V\%: 48 e 31, nas profundidades de 0-10 e 10- $20 \mathrm{~cm}$, respectivamente.

A aplicação do pó de serpentinito foi realizada manualmente no mês de setembro do ano de 2013 sendo efetuada a incorporação manual até aproximadamente $10 \mathrm{~cm}$ de profundidade. $\mathrm{O}$ serpentinito apresentava a seguinte composição: $\mathrm{SiO}_{2}$ (38,40\%), $\mathrm{Al}_{2} \mathrm{O}_{3}(1,31 \%), \mathrm{FeO}_{2}$ (12,66\%), $\mathrm{CaO}(0,66 \%), \mathrm{MgO}(35,07 \%), \mathrm{K}_{2} \mathrm{O}(0,01 \%), \mathrm{N}_{2} \mathrm{O}(<0,01 \%), \mathrm{TiO}_{2}(0,03 \%), \mathrm{MnO}$ $(0,09 \%)$ e $\mathrm{P}_{2} \mathrm{O}_{5}(0,02 \%)$.

Após a aplicação do serpentinito a área foi cultivada com soja (safra 13/14), trigo (2014) e soja (14/15). Todos esses três cultivos tiveram uma aplicação (dose de $300 \mathrm{~g} \mathrm{ha}^{-1}$ produto do comercial) para cada cultura com o bioativo Penergetic $\mathrm{k}$ (Bentonita em pó). O bioativo era constituído de: $\mathrm{SiO}_{2}$ (56\%), $\mathrm{Al}_{2} \mathrm{O}_{3}$ (16\%), $\mathrm{Fe}_{2} \mathrm{O}_{3}(4,0 \%), \mathrm{CaO}(4,0 \%), \mathrm{MgO}(4,0 \%), \mathrm{K}_{2} \mathrm{O}$ $(2,0 \%), \mathrm{Na}_{2} \mathrm{O}(0,4 \%)$ e micronutrientes $(3,5 \%)$. 
Aproximadamente 17 meses após a aplicação do serpentinito, foi semeada a forrageira Urochloa brizanta cv. Piatã (BRS Piatã) utilizando-se 3,5 $\mathrm{kg} \mathrm{ha}^{-1}$ de sementes puras viáveis. A semeadura foi mecanizada e realizada com o auxílio de um vicon e as sementes levemente incorporadas a profundidade de $2-3 \mathrm{~cm}$, com uso de grade niveladora. Durante o ciclo da forrageira não foi utilizado o bioativo, explorando somente benefício residual de 3 aplicações nas culturas antecessoras à semeadura da forrageira (soja, trigo e soja).

Aproximadamente 210 dias após a implantação da Urochloa, em agosto de 2015, e aproximadamente 23 meses após a aplicação do serpentinito, a parte aérea da forrageira foi cortada próximo ao nível do solo. Para esse procedimento, foi utilizado um triturador de palhada Triton® e os resíduos vegetais foram deixados na superfície do solo.

As coletas de fitomassa da Urochloa brizanta existente sobre a superfície do solo foram realizadas utilizando um quadro de metal, com $0,25 \mathrm{~m}^{2}$ de área útil, retirando-se, manualmente, todo o volume de resíduos superficiais contidos na área interna deste quadro. Foram realizadas três amostragens ao acaso, dentro de cada unidade experimental.

As amostras coletadas foram acondicionadas em sacos de papel, separadamente, e secas em estufa com circulação forçada de ar, a $65^{\circ} \mathrm{C}$, até peso constante. Após, procedeu-se à pesagem e quantificação da fitomassa seca de cada amostra.

Para a avaliação da decomposição da palhada da forrageira, as amostras do material vegetal foram acondicionadas em saquinhos de náilon (litter bags) com dimensão de $18 \mathrm{~cm} \times 28 \mathrm{~cm}$. As quantidades de palhadas (base seca a $65^{\circ} \mathrm{C}$ ), colocadas dentro de cada litter bag, foram proporcionais à massa seca produzida por tratamento. Colocaram-se cinco litter bags (deixados sobre o solo) sobre cada parcela de todos os tratamentos. As coletas dos litter bags foram feitas aos 30, 60, 90, $120 \mathrm{e}$ 150 dias após o manejo da forrageira.

\subsection{Variáveis analisadas}

\subsubsection{Taxa de cobertura da fitomassa da forrageira sobre solo}

Para a quantificação da porcentagem de cobertura do solo, foram realizadas avaliações a cada 30 dias, considerandose tempo zero a partir da instalação dos litter bags sobre o solo, até 150 dias após o corte da forrajeira. A cobertura vegetal foi estimada adaptando-se a metodologia de Pires et al. (2005), utilizando-se um quadriculo de ferro, medindo 0,5 $\mathrm{m} \times 0,3 \mathrm{~m}$, dividido em quadrinhos de $0,05 \mathrm{~m}$ x 0,05 m no total de 60 quadrinhos de avaliação (semelhante a uma tela quadriculada). Sempre que o espaço dentro de cada quadrinho coincidia com a presença de palha sob ele, era computada presença de cobertura. A cobertura de cada parcela foi calculada contabilizando-se a média de três avaliações em cada unidade experimental e convertendo-a em percentagem. Ao longo do tempo, para todas as avaliações, o equipamento foi colocado sempre nos mesmos pontos, anteriormente demarcados com estacas de bambu.

\subsubsection{Massa remanescente da fitomassa}

Para avaliar a massa seca remanescente da palhada, foi empregado o método das bolsas de decomposição litter bags (Thomas \& Asakawa, 1993), as quais foram confeccionadas com náilon com malha de $2 \mathrm{~mm}$ de abertura e dimensões de $18 \mathrm{x}$ $28 \mathrm{~cm}$. Cinco bolsas contendo os resíduos da forrageira em quantidade proporcional à da fitomassa seca produzida foram colocadas na superfície do solo de cada parcela 15 dias após o corte da braquiária. A massa remanescente da palhada foi determinada aos 30, 60, 90, 120 e 150 dias após instalação dos litter bags.

\subsubsection{Tempo de meia vida e constante $k$}

O cálculo do tempo de meia-vida $\left(T^{1 / 2}\right)$ da fitomassa da forrageira foi feito utilizando a fórmula matemática, de acordo com Paul e Clark (1989). $T^{1 / 2}=0,693 / k$, onde: $T^{1 / 2}=$ tempo de meia-vida para decomposição da fitomassa e da 
cobertura do solo (dias) e $k=$ constante de decomposição da fitomassa. A constante $\mathrm{K}$ foi calculada com referência na equação $X=X 0 e^{-k t}$ proposta por Rezende et al. (1999).

\subsection{Análise estatística}

Os dados obtidos de cada variável foram submetidos as análises de variância. Para as doses de pó de serpentinito, empregou-se a análise de regressão, quando constatada significância das doses. Os efeitos obtidos com os fatores qualitativos foram comparados através do teste de $\mathrm{t}$, a $5 \%$ de probabilidade.

\section{Resultados e Discussão}

\subsection{Avaliação da fitomassa de Urochloa brizantha}

Houve efeito significativo da interação doses de serpentinito x bioativo apenas para a massa seca da parte aérea. Ocorreu efeito significativo de doses, exceto para o tempo de meia vida e, de bioativo apenas para a constante $k$ e massa seca da parte aérea. Para todas as variáveis houve significância para o fator época (Tabela 1).

A produtividade de massa seca da parte aérea para o tratamento com bioativo, resultou em um comportamento linear crescente com produtividade estimada de 7,58 $\mathrm{Mg} \mathrm{ha}^{-1}$ na dose de $16,0 \mathrm{Mg} \mathrm{ha}^{-1}$ de serpentinito (Figura 2A). Já nos tratamentos que não receberam bioativo foi observado produtividade mínima de 5,31 $\mathrm{Mg} \mathrm{ha}^{-1}$ de MSPA, estimada na dose de 4,11 Mg ha-1 de serpentinito e à medida que aumentaram as doses de serpentinito, houve incremento de MSPA. Assim, o uso do bioativo mostrou-se interessante por proporcionar maior produção MSPA com menores doses de serpentinito, o que possivelmente ocorreu devido a maior ação microbiana ativada pelo uso de bioativo, decompondo frações lábeis da matéria orgânica (Kunde et al. 2016), aumentando a disponibilidade de nutrientes à Urochloa.

Heckler et al. (1998) abordam que 5,0 $\mathrm{Mg} \mathrm{ha}^{-1}$ de massa seca distribuída uniformemente sobre a superfície do solo em sistema de plantio direto é recomendável e Alvarenga et al. (2001) e Nunes et al. (2006) preconizam que a produção acima de 6,0 $\mathrm{Mg} \mathrm{ha}^{-1}$ de matéria seca é desejável para que a semeadura direta e cobertura do solo sejam satisfatórias. Portanto, as quantidades de matéria seca obtidas nesse trabalho com Urochloa Brizantha cv. Piatã são suficientes para implementação de sistema de semeadura direta, conforme Heckler et al. (1998). 
Tabela 1 - Valores de constante de decomposição $(k)$, tempo de meia vida $\left(\mathrm{T}^{1 / 2}\right)$, massa remanescente (MR), taxa de cobertura (TC) e massa seca da parte aérea (MSPA) de Urochloa Brizantha cv. Piatã em função das doses de serpentinito, épocas de coleta e uso do bioativo. Dourados - MS, 2018.

\begin{tabular}{|c|c|c|c|c|c|}
\hline & $(k)$ & $\mathbf{T}^{1 / 2}$ & MR & TC & MSPA \\
\hline $\begin{array}{c}\text { Doses (D) } \\
\text { Mg ha }^{-1}\end{array}$ & $\left(\mathrm{~g} \mathrm{~g}^{-1} \mathrm{dia}^{-1}\right)$ & (dias) & $(\%)$ & $(\%)$ & $\mathrm{kg} \mathrm{ha}^{-1}$ \\
\hline 0 & 0,0065 & 117,09 & 59,51 & 66,26 & 5.798 \\
\hline 2 & 0,0067 & 110,28 & 58,51 & 65,43 & 5.843 \\
\hline 4 & 0,0068 & 105,95 & 57,88 & 64,91 & 5.934 \\
\hline 8 & 0,0069 & 104,72 & 57,73 & 64,78 & 6.255 \\
\hline 16 & 0,0060 & 132,01 & 61,83 & 68,19 & 7.452 \\
\hline \multicolumn{6}{|l|}{ Épocas (E) } \\
\hline \multicolumn{6}{|l|}{ Dias } \\
\hline 0 & - & - & - & 97,70 & 9.480 \\
\hline 30 & 0,0081 & 87,33 & 78,42 & 81,12 & 7.694 \\
\hline 60 & 0,0073 & 97,24 & 64,57 & 67,44 & 6.402 \\
\hline 90 & 0,0060 & 118,34 & 58,49 & 56,66 & 5.382 \\
\hline 120 & 0,0055 & 148,65 & 53,04 & 48,77 & 4.636 \\
\hline 150 & 0,0061 & 118,34 & 40,97 & 43,79 & 4.164 \\
\hline \multicolumn{6}{|l|}{ Bioativo (B) } \\
\hline com & $0,0064 \mathrm{~b}$ & 113,37 & 59,85 & 66,55 & $5.836 \mathrm{~b}$ \\
\hline sem & $0,0068 \mathrm{a}$ & 114,65 & 58,34 & 65,28 & $6.677 \mathrm{a}$ \\
\hline \multicolumn{6}{|c|}{ Teste $\mathbf{t}^{(\mathbf{1})}$} \\
\hline Dose (D) & $*$ & NS & * & * & $* *$ \\
\hline Bioativo (B) & * & NS & NS & NS & $* *$ \\
\hline Época (E) & $*$ & $* *$ & $* *$ & $* *$ & $* *$ \\
\hline D x B & NS & NS & NS & NS & $* *$ \\
\hline$D \times E$ & NS & NS & NS & NS & NS \\
\hline $\mathrm{E} \times \mathrm{B}$ & NS & NS & NS & NS & NS \\
\hline $\mathrm{D} \times \mathrm{B} \times \mathrm{E}$ & NS & NS & NS & NS & NS \\
\hline Média & 0,0066 & 114,01 & 59,10 & 65,91 & $6.257,00$ \\
\hline CV1\% & 22,78 & 52,38 & 13,75 & 11,25 & 12,25 \\
\hline CV2 \% & 18,24 & 41,38 & 9,35 & 7,65 & 7,35 \\
\hline CV3 \% & 15,83 & 39,99 & 9,29 & 7,70 & 7,64 \\
\hline
\end{tabular}

(1) $* *, * \mathrm{e}^{\mathrm{NS}}$ : significativo a $1 \%, 5 \%$ e não significativo, respectivamente.

Médias seguidas de letras diferentes na coluna, diferem entre si pelo teste t de Student $(\mathrm{p}<0,05)$.

Fonte: Autores.

Outro fator que pode ter contribuído com o aumento da MSPA foi a correção do solo proporcionada pelo uso do serpentinito. O serpentinito proporciona melhorias nos atributos químicos do solo (Alovisi et al., 2019). Essa melhoria nos atributos químicos do solo contribui com o aumento na produção de massa da Urochloa, o que proporcionou permanência de maior quantidade de palhada sobre o solo ao longo do tempo, com possíveis interferências na persistência da palhada e na velocidade de liberação de nutrientes, podendo trazer benefícios às culturas subsequentes.

Quanto a decomposição da fitomassa da Urochloa verificou-se que a massa seca remanescente (MR) e taxa de cobertura (TC) foram influenciadas pelas doses de serpentinito e épocas de avaliação (Tabela 1). Observando as Figuras 2B, 2D, 3A e 3D, constatou-se similaridade no comportamento das variáveis MR e TC, para doses e épocas de avaliação, mostrando que a manutenção da massa seca sobre o solo reflete diretamente em seu potencial de cobertura ao longo do tempo.

As menores taxas de cobertura do solo $(64,68 \%)$ e massa remanescente $(57,68 \%)$ foram estimadas nas doses de 6,45 e $6,31 \mathrm{Mg} \mathrm{ha}^{-1}$ de serpentinito, respectivamente (Figuras 2B e 2D). 
Figura 2 - Valores médios de massa seca da parte aérea (A), taxa de cobertura (B), constante $K(\mathrm{C})$ e massa remanescente (D) na palhada da Urochloa Brizantha cv. Piatã, em função das doses de serpentinito. Dourados - MS, 2018. ns, * e ** não significativo, significativos a 5 e $1 \%$, com base na significância pelo teste $\mathrm{F}$.
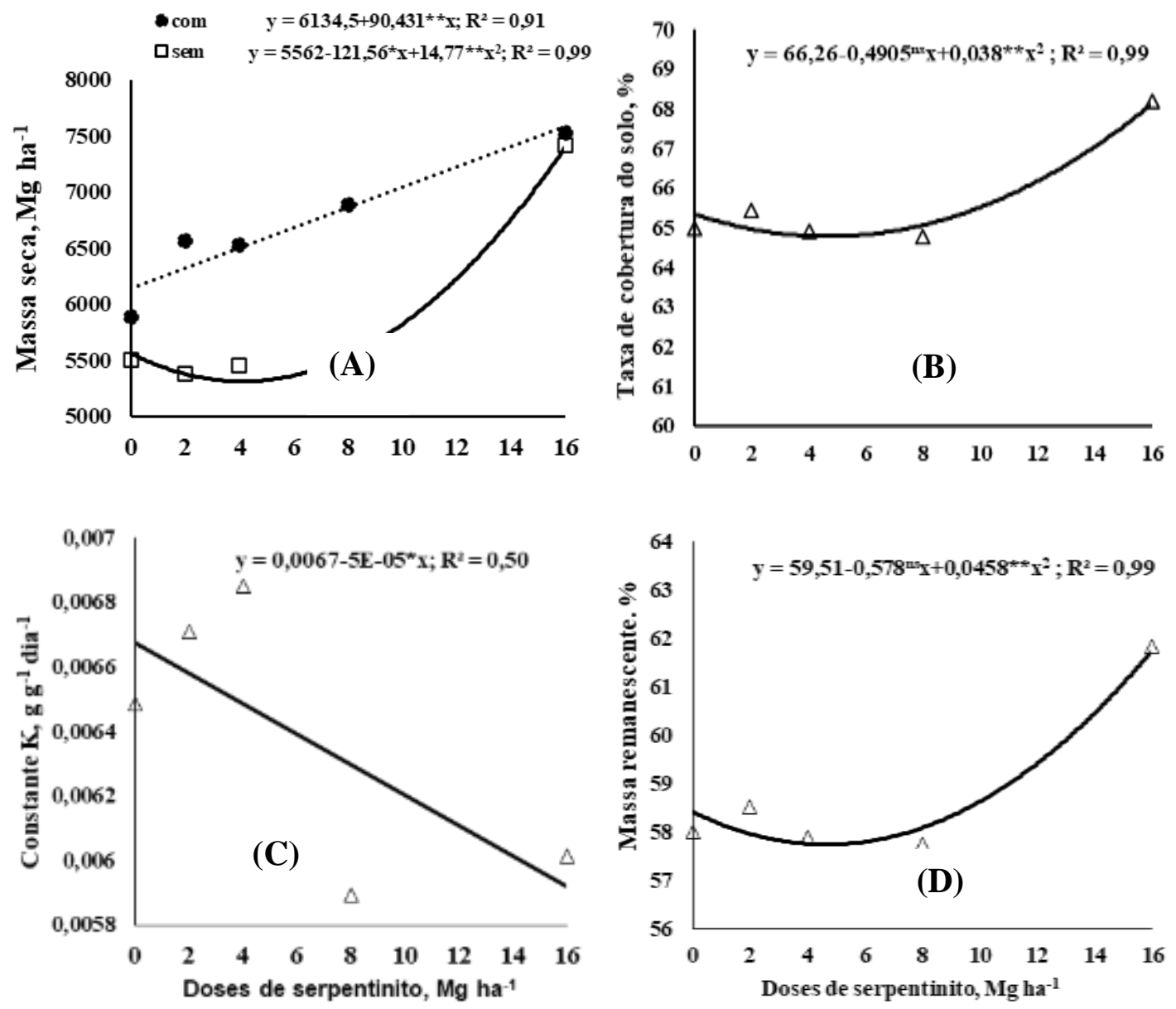

Fonte: Autores.

Para as diferentes épocas avaliadas, a taxa de cobertura (Figura 3A) e massa remanescente (Figura 3D) tiveram efeito linear decrescente, com taxa de cobertura estimada de $39 \%$ (redução de $56 \%$ em relação a cobertura inicial) e de massa remanescente estimada de $42 \%$ aos 150 dias (redução de 51\%). Valor semelhante para massa remanescente foi encontrado por Maluf et al. (2015) com palhada de Urochloa ruziziensis na região de Viçosa-MG, que obtiveram valor próximo de $40 \%$ aos 150 dias após o manejo. Rossi et al, avaliando massa remanescente de palhada de milho com braquiária obteve na região do cerrado de Goiás, durante primavera x verão, massa remanescente próximo a $45 \%$ até os 150 dias de avaliação.

Perin et al. (2004) preconiza que a cobertura do solo tem intensa importância térmica e hidrológica no solo, proporcionando sombreamento que evita a perda de energia pela transpiração e a incidência da radiação. A temperatura se mantem amena devido a redução da incidência de energia no solo, variando em relação a quantidade do substrato sobre a superfície e sua distribuição, que atua diminuindo a condutividade térmica e retardando o aquecimento do solo. Em especial, as plantas de cobertura favorecem a retenção de água na fração orgânica do solo, que pode se elevar de 4 a 6 vezes mais que seu peso e, as raízes exsudam uma grande variedade de compostos que favorece o desenvolvimento de uma vasta comunidade de microrganismos tornando ativa a ciclagem de nutrientes. 
Figura 3 - Valores médios da taxa de cobertura (A), constante $K(\mathrm{~B})$, tempo de 1/2 vida (C), massa remanescente (D) e massa seca (E) na palhada da Urochloa Brizantha cv. Piatã, em função das épocas de avaliação. Dourados - MS, 2018. * e ** significativos a 5 e $1 \%$, com base na significância pelo teste $\mathrm{F}$.
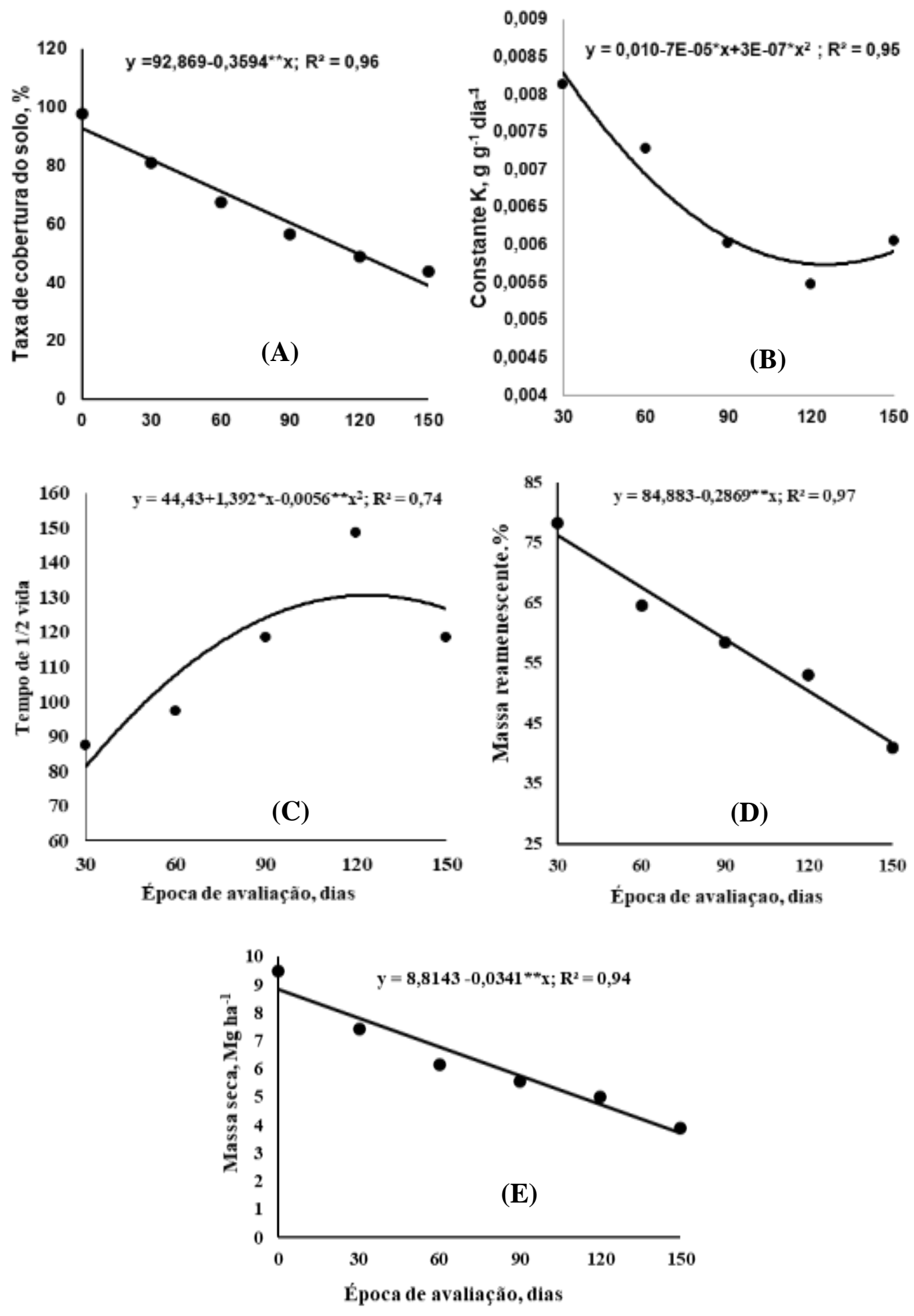

Fonte: Autores.

A massa seca da parte aérea produzida sob doses de serpentinito ao longo das épocas de avaliação foi linear decrescente, com produtividade estimada de 3,7 $\mathrm{Mg}$ ha $^{-1}$ aos 150 dias de avaliação (Figura 3E), com redução de massa correspondente a $56 \%$ até os 150 dias após o corte da forrageira. Resultados semelhantes foram encontrados por Kliemman 
(2006) que trabalhando com Urochloa brizanta sobre Latossolo Vermelho Distroférrico no cerrado Goiano, encontrou redução de $48 \%$ até os 150 dias, em estação chuvosa. No que se refere a manutenção de palha no sistema, é interessante destacar que mesmo aos 90 dias após o manejo (Figura 3E), ainda havia uma quantidade de massa seca próxima a $6 \mathrm{Mg} \mathrm{ha}^{-1}$, quantidade essa considerada por alguns autores como requisito importante para uma adequada condição no SPD (Alvarenga et al., 2001), contribuindo dessa forma para manutenção de umidade do solo, redução à exposição solar e também supressão de plantas daninhas.

Apesar da perda de massa correspondente a 56\% até os 150 dias (Figura 3E), o solo ainda apresentava uma taxa de cobertura de aproximadamente $40 \%$. Nos trinta primeiros dias da avaliação, a redução da massa remanescente foi de $14 \%$, valor esse menor dos que encontrados por Vivian et al. (2017) que obtiveram redução acima de $20 \%$ nos primeiros 30 dias com U. ruziziensis no estado de Santa Catarina. Ao avaliar a quantidade de massa seca remanescente mantida no solo, constatou-se que em 30 dias após o manejo manteve-se no solo 78,24\% da massa seca, ou seja, 21,76\% se decompuseram. A partir dos 30 dias do manejo a redução foi mais lenta até os 150 dias com decomposição próximo a $10 \%$ a cada 30 dias.

Observa-se na Figura 2C, que a constante de decomposição $(k)$ teve comportamento linear decrescente, com os menores valores estimados de $\mathrm{k}\left(0,0059 \mathrm{~g} \mathrm{~g}^{-1} \mathrm{dia}^{-1}\right)$ obtidos na maior de dose de serpentinito (16 $\left.\mathrm{Mg} \mathrm{ha}^{-1}\right)$, mostrando comportamento contrário a produção de MSPA (Figura 2A). Esse comportamento demonstra que pode haver relação entre volume de palha produzido e comportamento da constante $(k)$, ou seja, quanto maior os volumes de matéria seca sobre o solo menores serão os contatos de agentes decompositores, consequentemente menores a velocidade de decomposição, resultando em menores valores de $(k)$ o que é desejável. Em trabalho conduzido com palhada de cana, no entanto, Dietrich (2014) não encontrou relação entre a constante de velocidade de decomposição $(k)$ e a quantidade de palha na superfície do solo.

A constante de decomposição $(k)$ também foi significativamente influenciada pelo uso do bioativo. Os resultados obtidos na Tabela 1 mostram menor valor de $(k)$ de $\left(0,0064 \mathrm{~g} \mathrm{~g}^{-1} \mathrm{dia}^{-1}\right)$ para o uso de bioativo. O resultado obtido é diferente do comentado na literatura pois o uso de bioativadores são indicados como aceleradores nos processos de decomposição de resíduos no solo, o que parece não ter acontecido nesse estudo. Morais et al. (2015), testando tecnologia de bioativação do solo, identificaram, através da atividade microbiana, que o uso de bioativador juntamente com corretivos de solos resultou em incremento da atividade biológica do solo, contribuindo para a maior decomposição. Resultado semelhante também foi encontrado por Steffen et al. (2015) que observaram maior atividade biológica no solo e aumento da decomposição em palhada de trigo. No entanto, vale ressaltar que a cultura da Urochloa nesse trabalho não recebeu aplicação de bioativo, ficando somente submetido ao residual das aplicações das culturas que a antecederam.

O tempo máximo de meia-vida $\mathrm{T}^{1 / 2}$ (tempo necessário para decompor $50 \%$ da massa seca da fitomassa) foi de 131 dias, obtido aos 124 dias após manejo da Urochloa (Figura 3C). Os resultados obtidos reforçam a grande importância do uso de gramíneas para a formação de palhada no Cerrado brasileiro, pois mesmo em condições de elevada umidade de temperatura (Figura 1), o material apresentou elevado $\mathrm{T}^{1 / 2}$, contribuindo desta forma para que parte da palhada permaneça no solo, fornecendo proteção física, mantendo a umidade e contribuindo para o aumento dos teores de carbono orgânico no solo. Santos et al. (2014) obtiveram para a Urochloa brizanta após manejo com dessecação, $\mathrm{T}^{1 / 2}$ de 115 dias e Rossi et al. (2013) encontraram para a Urochloa ruziziensis $\mathrm{T}^{1 / 2}$ de 99 dias no cerrado goiano no período chuvoso.

Vale salientar, que os valores nas reduções de cobertura de solo e massa remanescente nesse trabalho podem ter sido influenciados pela elevada precipitação e temperatura (Figura 1) ocorrida no período que a Urochloa ficou no campo. Rossi et al. (2013) obtiveram, por exemplo, redução de cerca de 50\% na massa remanescente até os 120 dias após o manejo quando expuseram a palhada a campo no período chuvoso (primavera/verão) no cerrado goiano, contra redução de apenas cerca de $10 \%$ quando submetidas a campo no outono/inverno, pelo mesmo período. 


\section{Conclusão}

A aplicação do serpentinito aumentou a produção de MSPA, taxa de cobertura e massa remanescente de Urochoa brizantha cv. Piatã.

O uso do bioativo proporcionou maior produção de matéria seca da Urochloa brizantha cv. Piatã com menores doses de serpentinito.

\section{Agradecimentos}

À Fundação de Apoio ao Desenvolvimento do Ensino, Ciência e Tecnologia do Estado de Mato Grosso do Sul (FUNDECT), pelo financiamento da pesquisa e ao Conselho Nacional de Desenvolvimento Científico e Tecnológico (CNPq) pelas bolsas concedidas.

\section{Referências}

Alovisi, A. M. T., Rodrigues, R. B., Alovisi, A. A., Tebar, M. M., Villalba, L. A., Muglia, G. R. P., Palhano, M. S., Tokura, L. K., Cassol, C. J., Silva, R. S., Tokura, W. I., Gning. A., \& Kai, P. M. (2021). Uso do pó de rocha basáltica como fertilizante alternativo na cultura da soja, Research, Society and Development, 10(6), e33710615599. 10.33448/rsd-v10i6.15599.

Alovisi, A. A., Mauad, M., Alovisi, A. M. T., Tokura, L. K., Silva, R. S., Gomes, C. F., Ricieri, R. P. Siqueira, J. A. C., Oliveira, G. B., Lima, B. F., \& Araújo, W. A. (2019). Chemical Atributes of soil and Response of Wheat to Serpentinite in Direct Seeding System. Journal of Agricultural Science, 11(6), 460-468. $10.5539 /$ jas.v11n6p460

Alvares, C. A., Stapes, J. L., Sentelhas, P. C., Gonçalves, J. L. M., \& Sparovek, G. (2013). Köppen's climate classification map for Brazil. Meteorologische Zeitschrift, 22 (6), 711-728.

Alvarenga, R. C., Lara Cabezas, W. A., Cruz, J. C., \& Santana, D. P. (2001). Plantas de cobertura de solo para sistema plantio direto. Informe Agropecuário, $22,25-36$.

Araújo, L. S., \& Korndörfer, G. H. (2014). Papel do silício na produção, qualidade e controle de cigarrinha (deois flavopicta) da brachiaria decumbens, cultivada em solos degradados do triângulo mineiro. file://C:/Users/ havan/Desktop/pastas\%202014\%20a\%202016/janeiro\%202014/ Downloads /393914613-1-PB.pdf.

Ceribolla, E. C. Bioestimulante na Cultura da Soja (Glycine max. L). 2015. Trabalho de Conclusão de Curso (Graduação em Agronomia). Universidade Regional do Noroeste do Estado do Rio Grande do Sul.

Dietrich, G. (2014). Decomposição e liberação de nitrogênio da palha de cana-de-açúcar em função do ambiente e quantidade de palha. Dissertação de mestrado. Universidade Federal de Santa Maria Centro de Ciências Rurais - UFSM, Santa Maria, RS.

Duarte, W. M. (2010). Potencial das rochas flogopitito, granito e sienito na disponibilização de potássio em solos. Dissertação de mestrado. Centro de Ciências Agroveterinárias - UDESC.

Epstein, E. (1999). Silicon. Annual Review of Plant Physiology and Plant Molecular Biology, 50 (3), 641-664.

Friedman, H. (2013). The mineral and gemstone kingdom: minerals A-Z: group serpentine. http://www.minerals.net

Heckler, J. C., Hernani, L. C., \& Pitol, C. Palha. In: Salton, J. C., Hernani, L. C, \& Fontes, C. Z. (Org.). (1998). Sistema Plantio Direto: o produtor pergunta, a Embrapa responde (pp. 37-50). Brasília, DF: Embrapa SPI.

Kliemann, H. J., Braz, A. J. B. P., \& Silveira, P. M. (2006). Taxas de decomposição de resíduos de espécies de cobertura em Latossolo Vermelho Distroférrico. Pesquisa Agropecuária Tropical, 36, 21- 28.

Kunde, R. J., Lima, C. L. R., Silva, S. D. A., \& Pillon, C. N. (2016). Frações físicas da matéria orgânica em Latossolo cultivado com cana-de-açúcar no Rio Grande do Sul. Pesquisa Agropecuaria Brasileira, 51 (9), 1520-1528. 1590/S0100-204X2016000900051

Maluf, H. J. G., Soares, E. M. B., Silva, I. R., \& Silva, L. O. G. (2015). Decomposição de resíduos de culturas e mineralização de nutrientes em solo com diferentes texturas. Revista Brasileira de Ciência do Solo, 39, 1681-1689.

Melo, S. P., Korndörfer, G. H., Korndörfer, C. M., Lana, R. M. Q., \& Santana de, D. G. (2003). Acúmulo de silício e tolerância ao déficit hídrico em capins do gênero Brachiaria. Science Agrícola, 60 (4), 755-759.

Morais, R. M., Steffen, G. P., Maldaner, J., \& Saldanha, C. (2015). Promoção da atividade biológica do solo por manejo. Congresso Latinoamericano de agroecologia. http://sedici.unlp.edu.ar/bitstream/handle/ 10915/56256/

Nunes, U. R., Andrade Júnior, V. C., Silva, E. B., Santos, N. F., Costa, H. A. O., \& Ferreira, C. A. (2006). Produção de palhada de plantas de cobertura e rendimento do feijão em plantio direto. Pesquisa Agropecuária Brasileira, 41, 943-978.

Penergetic. Produtos. http://www.araunah.com/agro 
Research, Society and Development, v. 10, n. 7, e55310716821, 2021

(CC BY 4.0) | ISSN 2525-3409 | DOI: http://dx.doi.org/10.33448/rsd-v10i7.16821

Perin, A., Lima, E. A., Pereira, M. G., Teixeira, M. G., \& Guerra, J. G. M. (2004). Efeitos de coberturas vivas com leguminosas herbáceas perenes sobre a umidade e temperatura do solo. Agronomia, 38(1), 27-31.

Pires, F. R., Assis, R. L., Braz, A. J. B. P., Silva, G. P., Paiva, F. C., Macedo, R. S., Gomes, G. V., \& Cargnelutti Filho, A. (2005). Cobertura do solo por resíduos de espécies utilizadas como plantas de cobertura, cultivadas em safrinha, no Cerrado do sudoeste goiano. In: Congresso Brasileiro de Ciência Do Solo, Anais... Recife, Sociedade Brasileira de Ciência do Solo.

Rezende, C. P., Cantarutti, R. B., Braga, J. M., Gomide, J. A., Pereira, J. M., Ferreira, E., Tarré, R., Macedo, R., Alves, B. J. R., Urquiaga, S., Cadisch, G., Giller, K. E., \& Boddey, R. M. (1999). Litter deposition and disappearance in Brachiaria pastures in the Atlantic Forest region of the south of Bahia, Brazil. Nutrient Cycling in Agroecosystems, 54, 99-112.

Rossi, C. Q. P. M. G., Giacomo, M. B., Polidoro, J. C. (2013). Decomposição e liberação de nutrientes da palhada de braquiária, sorgo e soja em áreas de plantio direto no cerrado goiano. Semina, 34 (4), 1523-1534. 10.5433/1679-0359.2013v34n4p1523

Santos, F. C. S., Albuquerque Filho, M. R., Vilella, L., Ferreira, G. B., Carvalho, M. C. S., \& Viana, J. H. M. (2014). Decomposição e liberação de macronutrientes da palhada de milho e braquiária, sob integração lavoura-pecuária no cerrado Baiano. Revista Brasileira de Ciência do solo, 38 (6), 1855 1861. $10.1590 / \mathrm{S} 0100-06832014000600020$

Santos, H. G., Jacomine, P. K. T., Anjos, L. H. C., Oliveira, V. A., Lumbreras, J. F., Coelho, M. R., Almeida, J. A., Cunha, T. J. F, \& Oliveira, J. B. (2018). Sistema brasileiro de classificação de solos. 5. ed. Brasília, DF: Embrapa.

Silva, L. S. \& Bahnem, H. (2001). Liberação de nutrientes durante a decomposição de palhada de aveia preta (Avegna Strigosa) com diferentes teores de silício. Revista Brasileira de Ciência do solo, 25, 515-520

Steffen, G. P. K., Steffen, R. B., Trentin, E., Antoniolli, Z. I, \& Jacques, R. J. S. (2015). Atividade biológica e persistência de resíduos culturais depositados sob a superfície do solo, submetido à aplicação de Penergetic. https://issuu.com/diogolapaiva/docs/reedi_o_revista_artigos_final_we.

Tavares, E., Castilhos, Z., Luz, A., França, S., Cesar, R., \& Bertolino, L. C. (2010). Potencial de aplicação dos serpentinito como insumo na agricultura sustentável. Anais... Congresso Brasileiro de Rochagem. Embrapa Cerrado.

Teixeira, A. M. S., Sampaio, J. A., Garrido, F. M. S., Medeiros, M. E., Bertolino, L. C., \& Pérez, D. V. (2010). Estudo do uso de serpentinito como corretivo de solos agrícolas. II Simpósio de Minerais Industriais do Nordeste, Anais... Campina Grande - Paraíba. 10.13140/2.1.4079.5200.

Thomas, R. J. \& Asakawa, N. M. (1993). Decomposition of leaf litter from tropical forage grasses and legumes. Soil Biology Biochemistry, 23, $1351-1361$.

Trentin, E., Silveira, A. O., Antoniolli, Z. I., Jacques, R. J. S., Steffen R. B., Clasen B. E., Steffen G. P. K., \& Bassaco A. C. (2014). Efeito bioestimulador do Penergetic ${ }^{\circledR}$ na atividade microbiana e qualidade do solo. In: Ferbio, 2014. Fertilidade e biologia do solo: integração e tecnologias para todos.

Vivian, J. P., Menegat, N., Kaufmann, M. R., Sordi, A., \& Cericato, A. (2017). Potencial de braquiárias e panicum como plantas de cobertura em sistema de plantio direto. Unoesc \& Ciência, 8 (2), 129-136. 